\title{
Recidivism and Quality of Life among Former Drug Addicts: A Report Based on Prior Studies
}

\author{
Asbah Binti Razali', Nur Azah Binti Razali², Farimah Dokoushkani ${ }^{3}$, Aida Mehrad ${ }^{3}$ \\ ${ }^{1}$ Universiti Malaya (UM), Kuala Lumpur, Malaysia \\ ${ }^{2}$ Universiti Tun Hussien Onn Malaysia (UTHM), Batu Pahat, Malaysia \\ ${ }^{3}$ Universiti Putra Malaysia (UPM), Serdang, Malaysia \\ Email: asbahrazali@gmail.com
}

Received 8 January 2015; accepted 30 March 2015; published 2 April 2015

Copyright (C 2015 by authors and Scientific Research Publishing Inc.

This work is licensed under the Creative Commons Attribution International License (CC BY).

http://creativecommons.org/licenses/by/4.0/

(c) (i) Open Access

\begin{abstract}
The recidivism rate in substance abuse is linked to the failure of addicts to wean off their dependency on drugs, especially for addicts that had served their treatment and rehabilitation. This situation occurred because the addicts, after receiving treatment, faced environmental pressure and risky situations that triggered a negative response on their part. Based on previous studies, quality of life could be one factor that helps reduce former addicts' recidivism rate. A higher quality of life could also provide them with the strength and control necessary to resist reverting to drug abuse. This quality would positively affect the former addicts as it is linked to feelings of happiness, enjoyment, joy, and satisfaction. This paper touches on the definition of quality of life and previous studies regarding the quality of life factor and recidivism. The quality of life factor could hopefully provide a new perspective in rehabilitating former drug addicts and help them fight the urges to use drugs again. It is hoped this study report would be a guideline for recidivisms prevention programmes, especially for authorities responsible for managing problem related to drug abuse. The discussions in this paper hopefully could be useful to all related bodies in formulating a rehabilitation and prevention programme for former addicts to prevent them from lapsing. This situation would then help in reducing government burden in their efforts to tackle the problem.
\end{abstract}

\section{Keywords}

Recidivism, Quality of Life Could, Former Drug Abuse

\section{Introduction}

Recidivism in drug offence is linked to the failure of drug addicts in resisting their urges for drugs, especially for

How to cite this paper: Razali, A.B., Razali, N.A.B., Dokoushkani, F. and Mehrad, A. (2015) Recidivism and Quality of Life among Former Drug Addicts: A Report Based on Prior Studies. Open Journal of Social Sciences, 3, 44-49. 
patients that have finished their treatment period [1]. According to a report released by Substance Abuse and Mental Health Services Administration (SAMHSA), in 2009, more than 50\% of former addicts that finished treatment relapsed. This situation occurred as they faced environmental pressure and risks that provoked a negative response on their part. If they fail to meet these pressures, the risk of recidivism is high [2].

Efforts by past researchers to understand the recidivism phenomenon found multiple factors that contribute to the increase and decrease in relapse among addicts. Among them was quality of life after treatment [3]. Quality of life plays an important role in reducing the tendency of former addicts after receiving treatment and rehabilitation. Therefore, it is important to understand the concept of quality of life that serves as one factor in preventing relapse among addicts [4]. This study discusses the link between recidivism rates and quality of life among former drug addicts based on previous studies.

This paper touches on the definition of quality of life and previous studies on the quality of life factor and recidivism rates. This quality hopefully could provide a new perspective in rehabilitating former addicts and helping them fight their desire to use [5]. Therefore, this study of quality of life of former addicts and recidivism is an important one, as it focuses on the lifestyle quality of these addicts and it could be an important addition to current literature on this topic for future reference.

\section{Definition of Quality of Life}

There are multiple definitions explaining quality of life. Quality of life as an evaluation to the entirety of one's life and the highest quality of life occurs when the individual's physical and psychological needs are met [6]. According to Wellness Associates (2011) quality of life covers a number of aspects such as lifestyle, relationship between individuals and their environment, their passion, and emotion. It is a dynamic process, complex and encompassing various dimensions within an individual.

Quality of life is complex and difficult to define with the naked eye and each individual could achieve a good quality of life, based on the multiple dimensions of quality of life as seen by previous researchers. Focuses on one's quality of life based on a number of aspects such as self-acceptance, positive relations with others, autonomy, control over environment, life goals and self development [7]. He divides the aspects into two dimensions: positive such as fun, pleasure, and negative such as concern and depression. These dimensions cover aspects of emotions, mood and emotional response on the individual. Ones with high quality of life have more positive than negative dimensions, and conversely, ones with low quality of life are caused by more negative than positive dimensions [8].

Furthermore, pleasure is one of the elements that describe an individual with a positive quality of life. It is a portrayal of the level of individual expressing joy, satisfaction, happiness, and confidence. It also covers sub-dimensions such as cheerfulness, happiness, confidence, courage, and sensitivity [9]. On the other hand, a low quality of life shows an unstable emotion, quick temper, ease of getting into trouble, unsatisfied with their lives, fear, sadness, and guilt [10].

Quality of life found it to be synonymous with satisfaction with life, well-being, completeness, joy, hedonic level, happiness, fun, and success in life goals. Therefore, studies in psychology often use terms such as quality of life, happiness and subjective well-being in their research [11].

According to past researchers, quality of life should be seen from basic psychological needs that needs to be completed first [12]. This basic psychological needs refer to need for skill and feeling of being needed [13] need for power and autonomy [14]. When an individual reaches optimum level in fulfilling basic needs, they can develop and achieve a subjective level of happiness. The individual would likely be satisfied with every domain of their lives such as health, wealth, marriage, education, and others. It is also likely that individual unsatisfied with certain domains could affect their quality of life.

\section{Definition of Recidivism}

Recidivism is a process learned and to achieve rewards such as feeling satisfaction in order to reduce pain. The problem of recidivism is a continuation to addiction that haunts the addict. Recidivism usually occurs gradually for a number of weeks and proceeded by symptoms such as difficulty of sleeping, depression, sleeping all day in daytime and excessive anger for seemingly trivial things. Once a person takes or uses drugs, it is very difficult for them to let go of the habit even after a holistic rehabilitation process. This happens because of physical or psychological dependence on the substance consumed. As long as the two dependencies are not treated properly, 
it can affect the addict's chance for rehabilitation and drive them towards more dependence on drugs [15].

Outlines a number of characteristics of repeat addicts including change in attitude, being worrisome, defensive, compulsive, impulsive, and prefer to be alone. They will fell confused, unable to think clearly, unable to control emotions, difficulty in remembering, fatigued, and having a quick temper [16]. These would then drive an addict to relapse as they face various pressures such as psychological stress, interpersonal problems, desire to relapse, and environmental signals to relapse [17].

Furthermore, negative emotions, environmental signals, lack of problem-solving skills, unrealistic hopes, cognitive disturbance, changing moods, shame, guilt, and trauma also leads to drug abuse. These effects mean drug addicts are often disturbed and this then pressures them to relapse. Therefore, drug addicts require continuous follow-up treatment. However, addict rehabilitation process is too complex following their being described as being chronically disturbed and potentially relapsing after treatment [18].

\section{Previous Studies on the Quality of Life Factor and Recidivism Rate}

Until today, many researchers explore the positive psychological aspects by focusing more on efforts to increase quality of life of an individual [19]. Previous studies also agree that quality of life is closely linked to prediction of total satisfaction of life and could provide a positive view on the total life of the individual. This is because quality of life is a main indication of the individual well-being. In addition, in evaluating quality of life, an individual will determine the standard they feel compatible to them [20].

Previous studies found the quality of life factor is said to be able to reducing the risk of recidivism [21]. Quality of life here refers to comprehensive subjective cognitive evaluation in their lives. Studies use a score between 1 and 3.9 to show a low quality of life and a score of 4.0 or above for high satisfaction of life [22]. Studies show that two thirds of non-drug using respondents show a high level of quality of life and are within a positive environment, while one-third of respondents that use drug report dissatisfaction with their lives [23].

Studies the quality of life of 106 repeat addicts. Studies show the respondents admitting having a high quality of life after receiving non-continuous treatment within six months after the end of treatment period. Quality of life also increased in the first six months after receiving treatment. Evaluation of quality of life in this study covers evaluation of health and evaluation of effects of treatment. Studies also found that addicts that relapse within 30 days to six months are linked to feeling of dissatisfaction with their quality of life. This shows that the treatment process plays an important role in determining quality of life of addicts and determines the high or low percentage of recidivism among addicts [24].

A similar finding was reported by [25] which found that low quality of life would not only cause relapse, but also negatively affect the health of addicts. Studies also found that low quality of life contributes to the temptation to relapse. This tendency to relapse is also caused by declining health that affects the addicts' will to change. In their study, they suggest future researchers focus on the treatment process in their research, as according to them, studies on drug use and quality of life are mostly controlled demographic variables [26]. Therefore, efforts for future prevention and rehabilitation must target the quality of life of addicts that cause them to relapse even after the end of treatment.

The quality of life of 67 addicts in Belgium studies found that discrimination within a community against drug addicts leads to decline in quality of life and relapse, as addicts felt they are unable to recover and would reuse drugs [27]. Studies also found addicts' quality of life increase with presence of a chain of support such as family, friends, and environment. Most respondents found the social links affect their quality of life. A supportive environment could help in achieving high quality of life, while a less supportive environment means it was difficult for them to achieve high quality of life.

Studies found drug addicts have lower quality of life and self-worth compared to their non-drug addict counterparts explore the level of quality of life and self-worth of 76 addicts and 76 non-addicts within the 16 - 19 years age group [28]. This situation drove the Indian Government to hold drug addiction prevention programmes, especially among adolescents. Studies also found respondents that use drugs admit that factors such as lack of family supervision, peer pressure, lack of awareness on the effects of drugs, lack of exposure to cases of drugrelated deaths, all led to their addiction. In addition, they admitted that their quality of life increased with drug use, but it was only a short term fix.

Furthermore, [29] in his study of 130 adolescent drug addicts of the Hispanic community found their quality of life as being low because of them feeling worried. This feeling of worry contributes to recidivism, as they 
believed the worries will go away if they use drugs. Studies also found that low quality of life also leads to lower academic achievements, attitude problems, and emotional problems that would cause a low quality of life. Drug addicts, compared to non-drug users, have attitude problems and pressures in life, and as a result, they are less satisfied with their quality of life and would develop problematic behaviour.

Study that focuses on behaviour development of adolescents found that a low level of quality of life would bring stress to addicts' behaviour [30]. This study also shows a higher quality of life serves as a deterrent to negative behaviour. Quality of life could also prevent delinquent and aggressive behaviour when the adolescents faced stress. Study state that individuals dissatisfied with their lives would act violently as they are unable to manage their stress. A lack of stress and conflict management skills has also led them to contemplate suicide [31].

Drug addicts with high quality of life reported that they managed to overcome their addiction and physical health problems [32]. This proves that addicts that reports having high quality of life and satisfaction with their lives are less inclined to use drugs or relapse. Previous studies also agree that complete recidivism occur when addicts are not satisfied with their lives. Finally, a study in New Zealand also observes drug use and quality of life of adolescent addicts from a group of 1265 addicts (635 male, 630 female). Respondents were interviewed on the level of drug use and findings show that increase in drug use before they reach 21 years of age are linked to a decline in quality of life [33]. In addition, studies also found drug addicts that use drugs on more than 100 occasions report a lower quality of life. This shows that lower quality of life increases drug use and negatively affects satisfaction up to the adult years. Furthermore, the quality of life of addicts is useful information in calculating an addict's success to change and not relapse [34].

\section{Conclusion}

In respect to the aforementioned previous studies, a higher quality of life as reported by former addicts is expected to decrease any tendency to relapse. In addition, the nation would also face multiple losses due to loss in productive resources in the form of youths as well as the high cost incurred annually to reform former addicts. Identifying the best way to curb this problem is not easy as it is a critical issue. Therefore, all sides must cooperate to fight this problem so all addicts could live normal lives. Their rehabilitation and prevention of recidivism must be seen from a holistic standpoint as it negatively affects the addicts and individuals in their environment.

\section{References}

[1] Connors, G.J. and Maisto, S.A. (2005) Conceptualizations of Relapse: A Summary of Psychological and Psychobiological Models. Addiction, 91, 5-14. http://dx.doi.org/10.1046/j.1360-0443.91.12s1.17.x

[2] McHugh, R.K., Greenfield, S.F., Brooks, A.J., Gordon, S.M., Green, C.A. and Kropp, F. (2011) Substance Abuse Treatment Entry, Retention, and Outcome: A Review of the Literature. Drug and Alcohol Dependence, 86, 1-21.

[3] Tomczak, V.M. (2010) The Impact of Emotional Intelligence on Substance Abuse and Delinquency in a College Sample: The Comparison of Emotional Intelligence Traits versus Abilities. Retrieved from Pro Quest, UMI 3422981.

[4] Ramo, D.E. and Brown, S.A. (2008) Classes of Substance Abuse Relapse Situations: A Comparison of Adolescents and Adults. Psychology of Addictive Behaviors, 22, 372-379. http://dx.doi.org/10.1037/0893-164X.22.3.372

[5] Geisler, F.C.M., Vennewald, N., Kubiak, T. and Weber, H. (2010) The Impact of Heart Rate Variability on Subjective Well-Being Is Mediated by Emotion Regulation. Personality and Individual Differences, 49, 723-728. http://dx.doi.org/10.1016/j.paid.2010.06.015

[6] Diener, E. (2000) Subjective Well-Being: The Science of Happiness and a Proposal for a National Index. American Psychologist, 55, 34-43. http://dx.doi.org/10.1037/0003-066X.55.1.34

[7] Ryff, C.D. (1989) Happiness Is Everything, or Is It? Exploration on the Meaning of Psychological Well-Being. Journal of Personality and Social Psychology, 57, 1069-1081. http://dx.doi.org/10.1037/0022-3514.57.6.1069

[8] Ben-Zur, H. (2003) Happy Adolescents: The Link between Subjective Well-Being, Internal Resources, and Parental Factors. Journal of Youth and Adolescence, 32, 67-79. http://dx.doi.org/10.1023/A:1021864432505

[9] Kail, R.V. and Cavanaugh, J.C. (2007) Human Development: A life-Span View. Thomson Wadsworth, Australia.

[10] Snyder, C.R. and Lopez, S.J. (2002). Handbook of Positive Psychology. Oxford University Press, Oxford.

[11] Uchida, Y., Norasakkunkit, V. and Kitayama, S. (2004) Cultural Constructions of Happiness: Theory and Empirical Evidence. Journal of Happiness Studies, 5, 223-239. http://dx.doi.org/10.1007/s10902-004-8785-9

[12] Ryan, R.M. and Deci, E.L. (2000) On Happiness and Human Potentials: A Review of Research on Hedonic and Eu- 
daimonic Well-Being. Annual Review of Psychology, 52, 141-166. http://dx.doi.org/10.1146/annurev.psych.52.1.141

[13] Lu, L. and Gilmour, R. (2006) Culture and Conceptions of Happiness: Individual Oriented and Social Oriented swb. Journal of Happiness Studies, 5, 269-291. http://dx.doi.org/10.1007/s10902-004-8789-5

[14] Lee, D.Y., Park, S.H., Uhlemann, M.R. and Patsula, P. (1999) What Makes You Happy? A Comparison of Self-Reported Criteria of Happiness between Two Cultures. Social Indicators Research, 50, 351-362. http://dx.doi.org/10.1023/A:1004647517069

[15] Moss, R. and Cook, C.H. (2012) Maintenance and Relapse Prevention. In: Capuzzi, D. and Stauffer, M.D., Eds., Foundations of Addictions Counseling, 2nd Edition, Pearson Education, Upper Saddle River, 260-277.

[16] Gibson, D.M. and Myers, J.E. (2006) Perceived Stress, Wellness, and Mattering: A Profile of First-Year Citadel Cadets. Journal of College Student Development, 47, 647-660. http://dx.doi.org/10.1353/csd.2006.0065

[17] Anderson, K.G., Ramo, D.E. and Brown, S.A. (2006) Life Stress, Coping and Comorbid Youth: An Examination of the Stress-Vulnerability Model for Substance Relapse. Journal of Psychoactive Drugs, 38, 255-262. http://dx.doi.org/10.1080/02791072.2006.10399851

[18] Suldo, S.M., Riley, K. and Shaffer, E.S. (2006) Academic Correlates of Children and Adolescents' Life Satisfaction. School Psychology International, 27, 567-582. http://dx.doi.org/10.1177/0143034306073411

[19] Topolski, T.D., Patrick, D.L., Edwards, T.C., Huebner, C.E., Connell, F.A. and Mount, K. (2001) Quality of Life and Health-Risk Behaviors among Adolescents. Journal of Adolescent Health, 29, 426-435. http://dx.doi.org/10.1016/S1054-139X(01)00305-6

[20] Vecchio, G.M., Gerbino, M., Pastorelli, C., Del Bove, G. and Caprara, G.V. (2007) Multi-Faceted Self-Efficacy Beliefs as Predictors of Life Satisfaction in Late Adolescence. Personality and Individual Differences, 43, 1807-1818. http://dx.doi.org/10.1016/j.paid.2007.05.018

[21] Connolly, K.M. and Myers, J.E. (2003) Wellness and Mattering: The Role of Holistic Factors in Job Satisfaction. Journal of Employment Counseling, 40, 152-160. http://dx.doi.org/10.1002/j.2161-1920.2003.tb00866.x

[22] Lewis, T.F. and Myers, J.E. (2010) Wellness Factors as Predictors of Alcohol Use among Undergraduates: Implications for Prevention and Intervention. Journal of College Counseling, 13, 111-125. http://dx.doi.org/10.1002/j.2161-1882.2010.tb00053.x

[23] Miller, W.R., Westerberg, V.S., Harris, R.J. and Tonigan, J.S. (1996) What Predicts Relapse? Prospective Testing of Antecedent Models. Addiction, 91, 155-172.

[24] Mroczek, D.K. and Spiro, A. (2005) Change in Life Satisfaction during Adulthood: Findings from the Veterans Affairs Normative Aging Study. Journal of Personality and Social Psychology, 88, 189-202. http://dx.doi.org/10.1037/0022-3514.88.1.189

[25] Zullig, K.J., Valois, R.F., Huebner, E.S. and Drane, J.W. (2005) Adolescent Health Related Quality of Life and Perceived Satisfaction with Life. Quality of Life Research: An International Journal of Life Aspects of Treatment, Care and Rehabilitation, 14, 1573-1584. http://dx.doi.org/10.1007/s11136-004-7707-y

[26] Foster, J.H., Peters, T.J. and Marshall, E.J. (2000) Quality of Life Measures and Outcome in Alcohol-Dependent Men and Women. Alcohol, 22, 45-52. http://dx.doi.org/10.1016/S0741-8329(00)00102-6

[27] De Maeyer, J., Vanderplasschen, W. and Broekaert, E. (2009) Exploratory Study on Drug Users' Perspectives on Quality of Life: More than Health-Related Quality of Life? Social Indicators Research, 90, 107-126. http://dx.doi.org/10.1007/s11205-008-9315-7

[28] Rooks, L. (2010) The Relationship between Life Satisfaction and Substance Use in Adolescence. Graduate Theses and Dissertations, University of South Florida. http://scholarcommons.usf.edu/etd/1754

[29] Casas, F., Alsinet, C., Rosich, M., Huebner, E.S. and Laughlin, J.E. (2001) Cross-Cultural Investigation of the Multidimensional Students Life Satisfaction Scale with Spanish Adolescents. Third Conference of the International Society for Quality of Life Studies, Girona, 20-22 July 2000.

[30] Haranin, E.C., Huebner, E.S. and Suldo, S. (2007) Predictive and Incremental Validity of Global and Domain-Based Adolescent Life Satisfaction Reports. Journal of Psychoeducational Assessment, 25, 127-138. http://dx.doi.org/10.1177/0734282906295620

[31] Mac Donald, J.M., Piquero, A.R., Valois, R.F. and Zullig, K.J. (2005) The Relationship between Life Satisfaction, Risk-Taking Behaviors, and Youth Violence. Journal of Interpersonal Violence, 20, 1495-1518. http://dx.doi.org/10.1177/0886260505278718

[32] Laudet, A.B. and White, W. (2008) Recovery Capital as Prospective Predictor of Sustained Recovery, Life Satisfaction and Stress among Former Poly-Substance Users. Substance Use \& Misuse, 43, 27-54. http://dx.doi.org/10.1080/10826080701681473 
[33] Sinha, R. (2001) How Does Stress Increase Risk of Drug Abuse and Relapse? Psychopharmacology, 158, $343-359$. http://dx.doi.org/10.1007/s002130100917

[34] Ryff, C.D. and Keys, C.L. (1995) The Structure of Psychological Well-Being Revisited. Journal of Personality and Social Psychology, 69, 719-727. http://dx.doi.org/10.1037/0022-3514.69.4.719 